\title{
Synthesis and anti-oxidant activity of coumarinyl chalcones
}

\author{
Raj Keshwar Prasad* (10 and Kavita R. Loksh
}

\begin{abstract}
Background: The ability to inhibit oxidative stress has been established as the prime mechanism in treatment of several disease conditions. In view of this, two new series of coumarin-chalcone hybrid molecules (5a-o and $\mathbf{6} \mathbf{a}-\mathbf{0})$ were synthesized using various aromatic aldehydes. The structures of the compounds were confirmed using IR, $1 \mathrm{HNMR}$ and mass spectral analyses. The compounds were evaluated for their antioxidant potential against 2,2-diphenyl-1-picrylhydrazyl (DPPH) and hydroxyl radicals in scavenging assays.

Results: Compounds $\mathbf{5 o}$ and $\mathbf{5 k}$ exhibited significant antioxidant potential as compared to the standard drug (ascorbic acid).

Conclusions: It can be concluded that the coumarin-chalcone treatment have the potential to be optimized further to generate scaffolds capable to treat many pathological conditions.
\end{abstract}

Keywords: Coumarin, Chalcone, Antioxidant, Free radical, Vilsmeier-Haack, Claisen-Schmidt condensation

\section{Background}

Coumarins (2H-1-benzopyran-2-one) (I) contribute to more than 1300 secondary metabolites obtained from plants, bacteria, and fungi and therefore represent the largest class of phenolic substances found in plants [1]. The widespread availability of coumarins in nature has been instrumental for the wide spectrum biological activities exhibited by the natural coumarins. Several synthetic derivatives of coumarins have been explored for activities including antibacterial [2], antifungal [3], anticancer [4], anti-HIV [5], anti-inflammatory [6] etc. Al-Majedy et al. have reported a detailed review on the antioxidant action of synthetic coumarin derivatives [7].

Chalcones (II) are molecules containing a 1,3-diphenylprop-2-en-1-one obtained from the flavonoid class of natural products. Several chalcone compounds have been isolated from plant sources and aplenty synthetic derivatives have been produced in laboratories by substituting on the benzene rings. Most of the biological actions

*Correspondence: rajdavv2007@gmail.com

Department of Pharmacy, Oriental University, Madhya Pradesh,

Indore 453555, India exhibited by chalcones as owed to their antioxidant potential [8].

Reports have been made where linking two distinct moieties together using various functional groups or spacers has resulted in synergizing the action of the resulting molecules [9-17]. In persuasion to the reports, we envisaged to fuse coumarin and chalcone nucleuses to form novel conjugates and evaluate the antioxidant potential of the conjugates.

\section{Methods \\ General}

Melting points were determined using open capillary tubes and the reported results are uncorrected. Infrared spectra $(\mathrm{KBr})$ were obtained on Bruker FTIR spectrophotometer. ${ }^{1} \mathrm{H}$ NMR spectra were recorded on Bruker AVANCE-III $400 \mathrm{MHz}$ spectrometer in the suitable solvent using TMS as the internal standard and the mass spectra were obtained on Applied Biosystems 3200 Q-Trap spectrometer. Purity of the compounds was checked by TLC.

\section{Springer Open}

(C) The Author(s) 2021. Open Access This article is licensed under a Creative Commons Attribution 4.0 International License, which permits use, sharing, adaptation, distribution and reproduction in any medium or format, as long as you give appropriate credit to the original author(s) and the source, provide a link to the Creative Commons licence, and indicate if changes were made. The images or other third party material in this article are included in the article's Creative Commons licence, unless indicated otherwise in a credit line to the material. If material is not included in the article's Creative Commons licence and your intended use is not permitted by statutory regulation or exceeds the permitted use, you will need to obtain permission directly from the copyright holder. To view a copy of this licence, visit http://creativecommons.org/licenses/by/4.0/. 


\section{Chemistry}

The synthesis of the coumarin-chalcone hybrid molecules was accomplished according the reaction depicted in Scheme 1. The steps of the present scheme were adapted with modifications form the scheme reported by Tandel et al. [18] and Srikrishna et al. [19].

\section{4-chloro-2-oxo-2H-chromene-3-carbaldehyde (2)}

To a cooled solution of DMF $(25 \mathrm{~mL})$ and $\mathrm{POCl}_{3}(5 \mathrm{~mL})$ at $0-5{ }^{\circ} \mathrm{C}$ was added 4-hydroxycoumarin (1) $(5 \mathrm{mmol})$. The reaction mixture was stirred for $2-3 \mathrm{~h}$ at room temperature. On completion of reaction, as monitored on TLC (chloroform-acetone 3:2), the mixture was poured into ice-cold water $(30 \mathrm{~mL})$. The separated solid was filtered, washed with two $15 \mathrm{~mL}$ portions of water and dried to obtain. The crude product was recrystallized from a methanol gave pure carbaldehyde.

\section{4-Morpholino-2-oxo-2H-chromene-3-carbaldehyde (3)}

A solution of morpholine $(21.75 \mathrm{~g}, 20 \mathrm{mmol})$ in $10 \mathrm{ml}$ of dichloromethane was gradually added under constant stirring to an ice-cooled mixture of $2(2.09 \mathrm{~g}, 10 \mathrm{mmol})$ in $25 \mathrm{~mL}$ of dichloromethane. After stirring for $30 \mathrm{~min}$ at $0-5{ }^{\circ} \mathrm{C}$, the mixture was washed with three $10 \mathrm{~mL}$ portions of water to remove any unreacted morpholine and its salt. The organic phase was dried over $\mathrm{MgSO}_{4}$ and the solvent was evaporated under reduced pressure. The dry residual flakes were recrystallized from 1,4-dioxane to obtain pure 3 [20].

\section{(E)-3-(3-(4-aminophenyl)-3-oxoprop-1-enyl)-4-mor- pholino-2H-chromen-2-one (4)}

4-Morpholino-2-oxo-2H-chromene-3-carbaldehyde (3, $0.031 \mathrm{mmol})$ and 4 -amino acetophenone $(0.03 \mathrm{mmol})$ were dissolved in chloroform $(30 \mathrm{~mL})$. A catalytic amount of piperidine $(0.02 \mathrm{mmol})$ was added and the reaction mixture was refluxed for $1.5 \mathrm{~h}$. Chloroform was distilled out from the mixture and the residue was washed with methanol to obtain the pure chalcone (4) [21].

\section{General method of synthesis of 3-((E)-3-(4-((Z)-ben- zylideneamino)phenyl)-3-oxoprop-1-enyl)-4-mor- pholino-2H-chromen-2-one (5a-o)}

In a round bottom flask compound $4(0.0329 \mathrm{~mol})$ was dissolved in methanol $(20 \mathrm{~mL})$. Separately, substituted benzaldehyde $(0.0329 \mathrm{~mol})$ was dissolved in methanol $(20 \mathrm{~mL})$ in a beaker. The solution of substituted benzaldehyde was added drop by drop in to the solution of $\mathbf{4}$ with continuous stirring. On completion of addition, the mixture was allowed to reflux for $4 \mathrm{~h}$. On completion of reaction, the reaction mixture was poured in to an evaporating dish and the excess of solvent was removed under reduced pressure. The solid obtained crystallized using methanol [22].

3-((E)-3-(4-((Z)-4-hydroxybenzylideneamino)phenyl)-3-oxoprop-1-enyl)-4-morpholino-2H-chromen-2-one, 5 a Color: Dark Yellow; IR (KBr, cm $\left.{ }^{-1}\right)$ : 3420 (-OH str), 1652 ( $-\mathrm{C}=\mathrm{O}$ str, chalcone), $1712(-\mathrm{C}=\mathrm{O}$ str, coumarin $), 1098$ (-C-O-C str, morpholine), $1468(-\mathrm{C}=\mathrm{C}$ str, aromatic $) ;{ }^{1} \mathrm{H}$ NMR (DMSO, $\delta): 3.1-3.5\left(-\mathrm{N}\left(\mathrm{CH}_{2}\right)_{2}\right), 3.7-3.9\left(-\mathrm{O}\left(\mathrm{CH}_{2}\right)_{2}\right)$, 6.7-7.8 (H, Ar), $8.2(\mathrm{H}$, imine $), 4.9(\mathrm{OH})$; Mass: 481.6 $(\mathrm{M}+1)$.

\section{3-((E)-3-(4-((Z)-2-nitrobenzylideneamino)phenyl)-3-oxo-} prop-1-enyl)-4-morpholino-2H-chromen-2-one, $5 b$ Color: Dark Yellow; IR $\left(\mathrm{KBr}, \mathrm{cm}^{-1}\right)$ : 1658 ( $-\mathrm{C}=\mathrm{O}$ str, chalcone), 1719 ( $-\mathrm{C}=\mathrm{O}$ str, coumarin), 1098 (-C-O-C str, morpholine), 1465 ( $-\mathrm{C}=\mathrm{C}$ str, aromatic); ${ }^{1} \mathrm{H}$ NMR (DMSO, $)$ : $3.1-3.5\left(-\mathrm{N}\left(\mathrm{CH}_{2}\right)_{2}\right), 3.7-3.9\left(-\mathrm{O}\left(\mathrm{CH}_{2}\right)_{2}\right)$, 6.77.8 (H, Ar), $8.4\left(\mathrm{H}\right.$, imine), $8.2\left(\mathrm{H}\right.$, adj. $\left.\mathrm{NO}_{2}\right)$; Mass: 510.3 $(\mathrm{M}+1)$.

\section{3-((E)-3-(4-((Z)-3-nitrobenzylideneamino)phenyl)-3-oxo-} prop-1-enyl)-4-morpholino-2H-chromen-2-one, $5 \mathrm{C}$ Color: Pale Yellow; IR $\left(\mathrm{KBr}, \mathrm{cm}^{-1}\right): 1650(-\mathrm{C}=\mathrm{O}$ str, chalcone), 1710 ( $-\mathrm{C}=\mathrm{O}$ str, coumarin), 1095 (-C-O-C str, morpholine), 1468 ( $-\mathrm{C}=\mathrm{C}$ str, aromatic); ${ }^{1} \mathrm{H}$ NMR (DMSO, $)$ : $3.1-3.5\left(-\mathrm{N}\left(\mathrm{CH}_{2}\right)_{2}\right), 3.7-3.9\left(-\mathrm{O}\left(\mathrm{CH}_{2}\right)_{2}\right), 6.7-$ $7.8(\mathrm{H}, \mathrm{Ar}), 8.2\left(\mathrm{H}\right.$, imine), $8.5\left(\mathrm{H}\right.$, adj. $\left.\mathrm{NO}_{2}\right)$; Mass: 510.6 $(\mathrm{M}+1)$.

\section{3-((E)-3-(4-((Z)-4-nitrobenzylideneamino)phenyl)-3-oxo-} prop-1-enyl)-4-morpholino-2H-chromen-2-one, 5d Color: Dark Yellow; IR $\left(\mathrm{KBr}, \mathrm{cm}^{-1}\right)$ : 1658 ( $-\mathrm{C}=\mathrm{O}$ str, chalcone), 1712 ( $-\mathrm{C}=\mathrm{O}$ str, coumarin), 1098 (-C-O-C str, morpholine), $1470\left(-\mathrm{C}=\mathrm{C}\right.$ str, aromatic); ${ }^{1} \mathrm{H}$ NMR (DMSO, $\delta): ~ 3.1-3.5\left(-\mathrm{N}\left(\mathrm{CH}_{2}\right)_{2}\right)$, 3.7-3.9 $\left(-\mathrm{O}\left(\mathrm{CH}_{2}\right)_{2}\right)$, 6.7$7.8(\mathrm{H}, \mathrm{Ar}), 8.4\left(\mathrm{H}\right.$, imine), $8.2\left(\mathrm{H}, \mathrm{adj} . \mathrm{NO}_{2}\right)$; Mass: 510.5 $(\mathrm{M}+1)$.

3-((E)-3-(4-((Z)-2-hydroxybenzylideneamino)phenyl)-3-oxoprop-1-enyl)-4-morpholino-2H-chromen-2-one, 5 e Color: Dark Yellow; IR (KBr, cm $\left.{ }^{-1}\right)$ : 3422 (-OH str), 1648 ( $-\mathrm{C}=\mathrm{O}$ str, chalcone), 1710 ( $-\mathrm{C}=\mathrm{O}$ str, coumarin), 1098 (-C-O-C str, morpholine), $1468\left(-\mathrm{C}=\mathrm{C}\right.$ str, aromatic); ${ }^{1} \mathrm{H}$ NMR (DMSO, $\delta): 3.1-3.5\left(-\mathrm{N}\left(\mathrm{CH}_{2}\right)_{2}\right), 3.7-3.9\left(-\mathrm{O}\left(\mathrm{CH}_{2}\right)_{2}\right)$, 6.7-7.8 (H, Ar), $8.2(\mathrm{H}$, imine $), 4.9(\mathrm{OH})$; Mass: 481.3 $(\mathrm{M}+1)$.

3-((E)-3-(4-((Z)-3,4-dimethoxybenzylideneamino)phenyl)-3-oxoprop-1-enyl)-4-morpholino-2H-chromen-2-one, $5 f$

Color: Pale Yellow; IR $\left(\mathrm{KBr}, \mathrm{cm}^{-1}\right): 1652(-\mathrm{C}=\mathrm{O}$ str, chalcone), 1712 ( $-\mathrm{C}=\mathrm{O}$ str, coumarin), 1098 (-C-O-C 
<smiles>O=c1ccc2ccccc2o1</smiles>

I<smiles>O=c1cc(O)c2ccccc2o1</smiles>

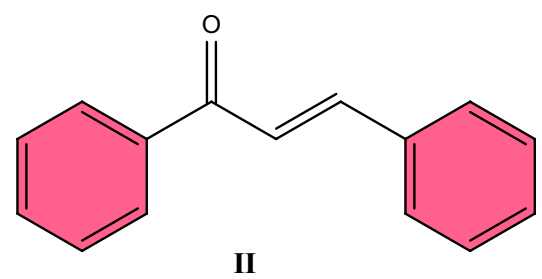

II<smiles>O=Cc1c(Cl)c2ccccc2oc1=O</smiles>

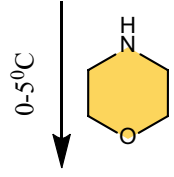<smiles></smiles><smiles>O=Cc1c(N2CCOCC2)c2ccccc2oc1=O</smiles>

EtOH, Piperidine



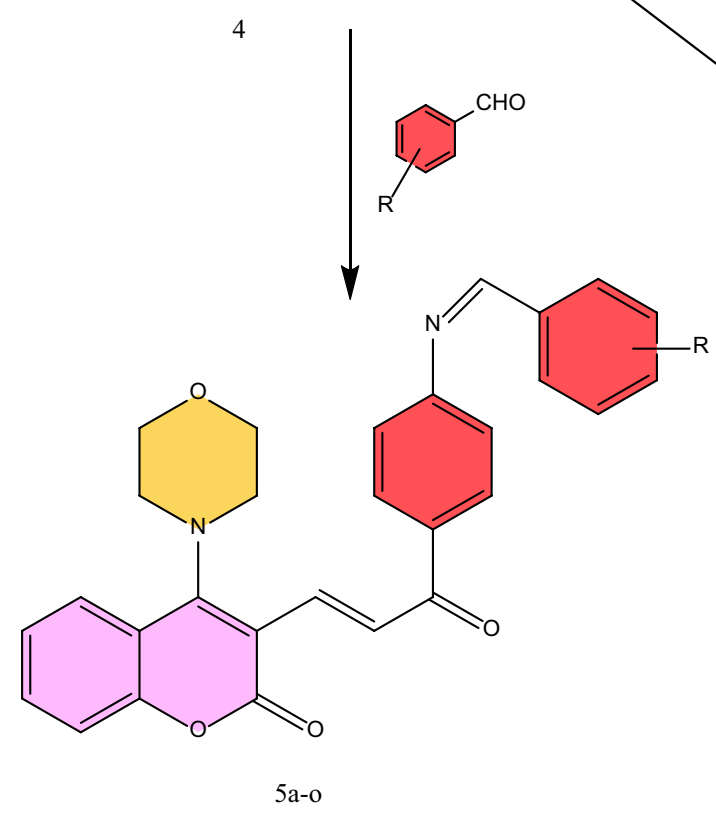<smiles>CC(=O)/C=C/c1c(C)c2ccccc2oc1=O</smiles>

3
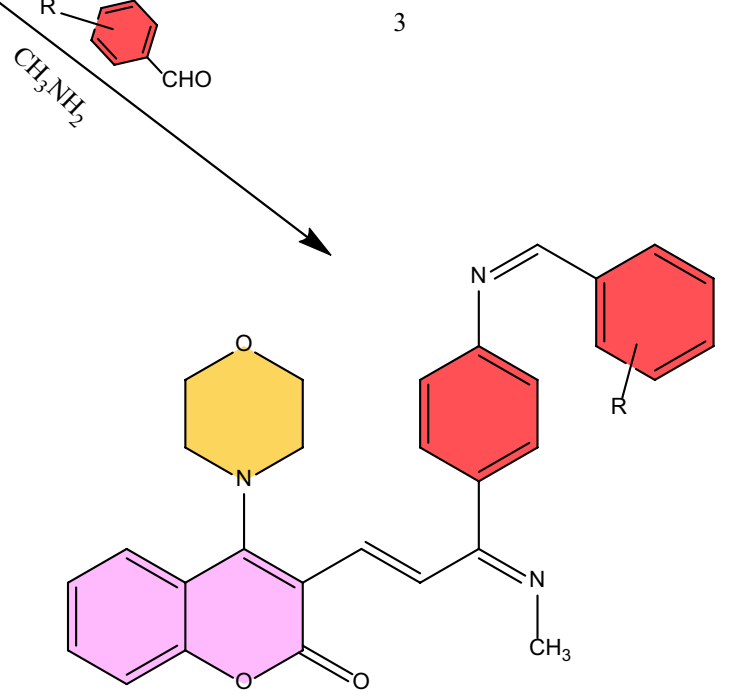

6a-o

$\mathrm{R}_{(\mathrm{a}-\mathrm{o})}=4-\mathrm{OH}, 2-\mathrm{NO}_{2}, 3-\mathrm{NO}_{2}, 4-\mathrm{NO}_{2}, 2-\mathrm{OH}, 2$,4-dimethoxy, 2-Cl, 3-Cl, H, 4-OCH 3 , 3-methoxy-4-OH, 3-Br, 4- $\mathrm{Br}, 4-\mathrm{Cl}, 4-\mathrm{N}\left(\mathrm{CH}_{3}\right) 2$ Scheme 1 Reaction scheme for the synthesis of coumarin-chalcone conjugates 
str, morpoline), 1468 ( $-\mathrm{C}=\mathrm{C}$ str, aromatic); ${ }^{1} \mathrm{H}$ NMR (DMSO, $\delta): 3.1-3.5\left(-\mathrm{N}\left(\mathrm{CH}_{2}\right)_{2}\right), 3.7-3.9\left(-\mathrm{O}\left(\mathrm{CH}_{2}\right)_{2}\right)$, 6.7-7.8 $(\mathrm{H}, \mathrm{Ar}), 8.3(\mathrm{H}$, imine $), 3.8\left(\mathrm{CH}_{3}\right.$, methoxy); Mass: $525.4(\mathrm{M}+1)$.

3-((E)-3-(4-((Z)-2-chlorobenzylideneamino)phenyl)-3-oxoprop-1-enyl)-4-morpholino-2H-chromen-2-one, $5 \mathrm{~g}$

Color: Dark Yellow; IR $\left(\mathrm{KBr}, \mathrm{cm}^{-1}\right): 1650(-\mathrm{C}=\mathrm{O}$ str, chalcone), 1715 ( $-\mathrm{C}=\mathrm{O}$ str, coumarin), 1097 ( $-\mathrm{C}-\mathrm{O}-\mathrm{C}$ str, morpoline), $1463(-\mathrm{C}=\mathrm{C}$ str, aromatic), 765 (C$\mathrm{Cl}$ ); ${ }^{1} \mathrm{H}$ NMR (DMSO, $\left.\delta\right): 3.1-3.5\left(-\mathrm{N}\left(\mathrm{CH}_{2}\right)_{2}\right), 3.7-3.9$ $\left(-\mathrm{O}\left(\mathrm{CH}_{2}\right)_{2}\right), 6.7-7.8(\mathrm{H}, \mathrm{Ar}), 8.2(\mathrm{H}$, imine); Mass: 500.1 $(\mathrm{M}+1)$.

3-((E)-3-(4-((Z)-3-chlorobenzylideneamino)phenyl)-3-oxoprop-1-enyl)-4-morpholino-2H-chromen-2-one, $5 \mathrm{~h}$ Color: Dark Yellow; IR (KBr, $\left.\mathrm{cm}^{-1}\right)$ : $1650(-\mathrm{C}=\mathrm{O}$ str, chalcone), 1715 ( $-\mathrm{C}=\mathrm{O}$ str, coumarin), 1097 (-C-O-C str, morpoline), $1463(-\mathrm{C}=\mathrm{C}$ str, aromatic), 755 (C$\mathrm{Cl}) ;{ }^{1} \mathrm{H}$ NMR (DMSO, $)$ : $3.1-3.5\left(-\mathrm{N}\left(\mathrm{CH}_{2}\right)_{2}\right), 3.7-3.9$ $\left(-\mathrm{O}\left(\mathrm{CH}_{2}\right)_{2}\right), 6.7-7.8(\mathrm{H}, \mathrm{Ar}), 8.2(\mathrm{H}$, imine); Mass: 500.1 $(\mathrm{M}+1)$.

3-((E)-3-(4-((Z)-benzylideneamino)phenyl)-3-oxoprop-1-enyl)-4-morpholino-2H-chromen-2-one, $5 \mathrm{i}$ Color: Dark Yellow; IR ( $\left.\mathrm{KBr}, \mathrm{cm}^{-1}\right)$ : $1652(-\mathrm{C}=\mathrm{O}$ str, chalcone), 1712 ( $-\mathrm{C}=\mathrm{O}$ str, coumarin), 1098 (-C-O-C str, morpoline), 1468 ( $-\mathrm{C}=\mathrm{C}$ str, aromatic); ${ }^{1} \mathrm{H}$ NMR (DMSO, $)$ : $3.1-3.5\left(-\mathrm{N}\left(\mathrm{CH}_{2}\right)_{2}\right), 3.7-3.9\left(-\mathrm{O}\left(\mathrm{CH}_{2}\right)_{2}\right), 6.7-$ 7.8 (H, Ar), 8.2 (H, imine); Mass: $467.3(\mathrm{M}+1)$.

3-((E)-3-(4-((Z)-4-methoxybenzylideneamino)phenyl)-3-oxoprop-1-enyl)-4-morpholino-2H-chromen-2-one. 5j

Color: Yellow; IR $\left(\mathrm{KBr}, \mathrm{cm}^{-1}\right)$ : $1655(-\mathrm{C}=\mathrm{O}$ str, chalcone), 1718 ( $-\mathrm{C}=\mathrm{O}$ str, coumarin), 1095 (-C-O-C str, morpoline), 1466 (-C $=\mathrm{C}$ str, aromatic); ${ }^{1} \mathrm{H}$ NMR (DMSO, $)$ : $3.1-3.5\left(-\mathrm{N}\left(\mathrm{CH}_{2}\right)_{2}\right), 3.7-3.9\left(-\mathrm{O}\left(\mathrm{CH}_{2}\right)_{2}\right), 6.7-$ 7.8 (H, Ar), 8.2 (H, imine), 3.8 ( $\mathrm{H}$, methoxy); Mass: 498.0 $(\mathrm{M}+1)$.

\section{3-((E)-3-(4-((Z)-4-hydroxy-3-methoxybenzylide-} neamino)phenyl)-3-oxoprop-1-enyl)-4-morpholino-2H-chromen-2-one, $5 \mathrm{k}$

Color: Dark Yellow; IR (KBr, cm ${ }^{-1}$ ): 3600 (-OH str), 1650 ( $-\mathrm{C}=\mathrm{O}$ str, chalcone), $1717 \quad(-\mathrm{C}=\mathrm{O}$ str, coumarin), 1097 (-C-O-C str, morpoline), 1468 ( $-\mathrm{C}=\mathrm{C}$ str, aromatic); ${ }^{1} \mathrm{H}$ NMR (DMSO, $): 3.1-3.5\left(-\mathrm{N}\left(\mathrm{CH}_{2}\right)_{2}\right), 3.7-3.9$ $\left(-\mathrm{O}\left(\mathrm{CH}_{2}\right)_{2}\right), 6.7-7.8(\mathrm{H}, \mathrm{Ar}), 8.2(\mathrm{H}$, imine $), 5.1(\mathrm{OH}), 3.7$ ( $\mathrm{H}$, methoxy); Mass: $513.8(\mathrm{M}+1)$.
3-((E)-3-(4-((Z)-3-bromobenzylideneamino)phenyl)-3-oxoprop-1-enyl)-4-morpholino-2H-chromen-2-one, $5 \mathrm{I}$

Color: Dark Yellow; IR $\left(\mathrm{KBr}, \mathrm{cm}^{-1}\right): 1650(-\mathrm{C}=\mathrm{O}$ str, chalcone), 1710 ( $-\mathrm{C}=\mathrm{O}$ str, coumarin), 1094 (-CO-C str, morpoline), 1459 ( $-\mathrm{C}=\mathrm{C}$ str, aromatic), 610 $(\mathrm{C}-\mathrm{Br}) ;{ }^{1} \mathrm{H}$ NMR (DMSO, $)$ : $3.1-3.5\left(-\mathrm{N}\left(\mathrm{CH}_{2}\right)_{2}\right), 3.7-$ $3.9\left(-\mathrm{O}\left(\mathrm{CH}_{2}\right)_{2}\right), 6.7-7.8(\mathrm{H}, \mathrm{Ar}), 8.2(\mathrm{H}$, imine); Mass: $543.3(\mathrm{M}+1)$.

3-((E)-3-(4-((Z)-4-bromobenzylideneamino)phenyl)-3-oxoprop-1-enyl)-4-morpholino-2H-chromen-2-one, $5 \mathrm{~m}$

Color: Dark Yellow; IR (KBr, $\left.\mathrm{cm}^{-1}\right): 1650$ ( $-\mathrm{C}=\mathrm{O}$ str, chalcone), 1710 ( $-\mathrm{C}=\mathrm{O}$ str, coumarin), 1094 (-CO-C str, morpoline), 1459 ( $-\mathrm{C}=\mathrm{C}$ str, aromatic), 610 $(\mathrm{C}-\mathrm{Br}) ;{ }^{1} \mathrm{H}$ NMR (DMSO, $\left.\delta\right): 3.1-3.5\left(-\mathrm{N}\left(\mathrm{CH}_{2}\right)_{2}\right), 3.7-$ $3.9\left(-\mathrm{O}\left(\mathrm{CH}_{2}\right)_{2}\right), 6.7-7.8(\mathrm{H}, \mathrm{Ar}), 8.2(\mathrm{H}$, imine); Mass: $543.3(\mathrm{M}+1)$.

3-((E)-3-(4-((Z)-4-chlorobenzylideneamino)phenyl)-3-oxoprop-1-enyl)-4-morpholino-2H-chromen-2-one, $5 n$ Color: Dark Yellow; IR ( $\left.\mathrm{KBr}, \mathrm{cm}^{-1}\right): 1652(-\mathrm{C}=\mathrm{O}$ str, chalcone), 1710 ( $-\mathrm{C}=\mathrm{O}$ str, coumarin), 1097 (-CO-C str, morpoline), 1463 ( $-\mathrm{C}=\mathrm{C}$ str, aromatic), 763 $(\mathrm{C}-\mathrm{Cl}) ;{ }^{1} \mathrm{H}$ NMR (DMSO, $\left.\delta\right): 3.1-3.5\left(-\mathrm{N}\left(\mathrm{CH}_{2}\right)_{2}\right), 3.7-$ $3.9\left(-\mathrm{O}\left(\mathrm{CH}_{2}\right)_{2}\right), 6.7-7.8(\mathrm{H}, \mathrm{Ar}), 8.2(\mathrm{H}$, imine); Mass: $500.1(\mathrm{M}+1)$.

3-((E)-3-(4-((Z)-4-(dimethylamino)benzylideneamino)phenyl)-3-oxoprop-1-enyl)-4-morpholino-2H-chromen-2-one, 50

Color: Pale Yellow; IR (KBr, $\left.\mathrm{cm}^{-1}\right): 1652(-\mathrm{C}=\mathrm{O}$ str, chalcone), 1712 (-C=O str, coumarin), 1096 (-C-O-C str, morpoline), 1468 ( $-\mathrm{C}=\mathrm{C}$ str, aromatic); $1 \mathrm{H} \mathrm{NMR} \mathrm{(DMSO, \delta ):}$ 3.1-3.5 $\left(-\mathrm{N}\left(\mathrm{CH}_{2}\right)_{2}\right), 3.7-3.9\left(-\mathrm{O}\left(\mathrm{CH}_{2}\right)_{2}\right), 6.7-7.8(\mathrm{H}, \mathrm{Ar}), 8.2$ ( $\mathrm{H}$, imine), $2.9\left(\mathrm{H}, \mathrm{N}-\mathrm{CH}_{3}\right)$; Mass: $508.6(\mathrm{M}+1)$.

General method of synthesis of 3-((1E,3E)-3-(4-((Z)-benzylideneamino)phenyl)-3-(methylimino)prop-1-enyl)-4-morpholino-2H-chromen-2-one (6a-o)

A mixture of $\mathbf{5}(\mathbf{a}-\mathbf{o})(5 \mathrm{mmol})$, methylamine $(5 \mathrm{mmol})$ and acetic acid $(10 \mathrm{~mL})$ was stirred at room temperature for $10 \mathrm{~min}$. Then, the mixture was poured into ice-cold water $(30 \mathrm{~mL})$. The separated solid was filtered, washed with two $5 \mathrm{~mL}$ portions of aqueous acetic acid (1:1) and dried. The crude product was recrystallized from suitable 1,4-dioxane to obtain pure compounds $\mathbf{6 a - o}[19,22]$.

\section{3-((1E,3E)-3-(4-(((Z)-4-hydroxybenzylidene)amino)} phenyl)-3-(methylimino)prop-1-en-1-yl)-4-morpholino-2H-chromen-2-one, $6 a$

Color: Dark Yellow; IR (KBr, cm $\left.{ }^{-1}\right)$ : $3420 \quad(-\mathrm{OH}$ str), $1652(-\mathrm{C}=\mathrm{O}$ str, chalcone $), 1712(-\mathrm{C}=\mathrm{O}$ str, 
coumarin), 1098 (-C-O-C str, morpholine), 1468 $\left(-\mathrm{C}=\mathrm{C}\right.$ str, aromatic); ${ }^{1} \mathrm{H}$ NMR (DMSO, $\left.\delta\right): 3.1-3.5$ $\left(-\mathrm{N}\left(\mathrm{CH}_{2}\right)_{2}\right), 3.7-3.9\left(-\mathrm{O}\left(\mathrm{CH}_{2}\right)_{2}\right), 6.7-7.8(\mathrm{H}, \mathrm{Ar}), 8.2$ ( $\mathrm{H}$, imine), $4.9(\mathrm{OH}), 3.5\left(\mathrm{~N}-\mathrm{CH}_{3}\right)$; Mass: $493.5(\mathrm{M}+1)$.

\section{3-((1E,3E)-3-(methylimino)-3-(4-)((Z)-2-nitroben- zylidene)amino)phenyl)prop-1-en-1-yl)-4-mor- pholino-2H-chromen-2-one, $6 b$}

Color: Dark Yellow; IR $\left(\mathrm{KBr}, \mathrm{cm}^{-1}\right): 1658(-\mathrm{C}=\mathrm{O}$ str, chalcone), 1719 ( $-\mathrm{C}=\mathrm{O}$ str, coumarin), 1098 (-C-O-C str, morpholine), $1465\left(-\mathrm{C}=\mathrm{C}\right.$ str, aromatic); ${ }^{1} \mathrm{H}$ NMR (DMSO, $\delta): 3.1-3.5\left(-\mathrm{N}\left(\mathrm{CH}_{2}\right)_{2}\right), 3.7-3.9\left(-\mathrm{O}\left(\mathrm{CH}_{2}\right)_{2}\right), 6.7-$ $7.8(\mathrm{H}, \mathrm{Ar}), 8.4(\mathrm{H}$, imine $), 8.2\left(\mathrm{H}\right.$, adj. $\left.\mathrm{NO}_{2}\right) 3.4\left(\mathrm{~N}-\mathrm{CH}_{3}\right)$; Mass: $525.7(\mathrm{M}+1)$.

\section{3-((1E,3E)-3-(methylimino)-3-(4-(((Z)-3-nitroben-} zylidene)amino)phenyl)prop-1-en-1-yl)-4-morpholino-2H-chromen-2-one, $6 \mathrm{c}$

Color: Pale Yellow; IR $\left(\mathrm{KBr}, \mathrm{cm}^{-1}\right): 1650(-\mathrm{C}=\mathrm{O}$ str, chalcone), 1710 ( $-\mathrm{C}=\mathrm{O}$ str, coumarin), 1095 ( $-\mathrm{C}-\mathrm{O}-\mathrm{C}$ str, morpholine), $1468\left(-\mathrm{C}=\mathrm{C}\right.$ str, aromatic); ${ }^{1} \mathrm{H}$ NMR (DMSO, $\delta): 3.1-3.5\left(-\mathrm{N}\left(\mathrm{CH}_{2}\right)_{2}\right), 3.7-3.9\left(-\mathrm{O}\left(\mathrm{CH}_{2}\right)_{2}\right)$, 6.7$7.8(\mathrm{H}, \mathrm{Ar}), 8.2\left(\mathrm{H}\right.$, imine), $8.5\left(\mathrm{H}\right.$, adj. $\left.\mathrm{NO}_{2}\right), 3.5\left(\mathrm{~N}-\mathrm{CH}_{3}\right)$, $3.5\left(\mathrm{~N}-\mathrm{CH}_{3}\right)$; Mass: $525.6(\mathrm{M}+1)$.

\section{3-((1E,3E)-3-(methylimino)-3-(4-(((Z)-4-nitroben-} zylidene)amino)phenyl)prop-1-en-1-yl)-4-morpholino-2H-chromen-2-one, $6 d$

Color: Dark Yellow; IR (KBr, $\left.\mathrm{cm}^{-1}\right)$ : 1658 (-C=O str, chalcone), 1712 ( $-\mathrm{C}=\mathrm{O}$ str, coumarin), 1098 (-C-O-C str, morpholine), 1470 ( $-\mathrm{C}=\mathrm{C}$ str, aromatic); ${ }^{1} \mathrm{H}$ NMR (DMSO, $\delta): 3.1-3.5\left(-\mathrm{N}\left(\mathrm{CH}_{2}\right)_{2}\right), 3.7-3.9\left(-\mathrm{O}\left(\mathrm{CH}_{2}\right)_{2}\right)$, 6.7-7.8 (H, Ar), $8.4\left(\mathrm{H}\right.$, imine), $8.2\left(\mathrm{H}\right.$, adj. $\left.\mathrm{NO}_{2}\right), 3.5$ $\left(\mathrm{N}-\mathrm{CH}_{3}\right)$; Mass: $525.5(\mathrm{M}+1)$.

\section{3-((1E,3E)-3-(4-(((Z)-2-hydroxybenzylidene)amino)} phenyl)-3-(methylimino)prop-1-en-1-yl)-4-morpholino-2H-chromen-2-one, $6 e$ Color: Dark Yellow; IR (KBr, cm ${ }^{-1}$ ): 3422 (-OH str), 1648 ( $-\mathrm{C}=\mathrm{O}$ str, chalcone), $1710 \quad(-\mathrm{C}=\mathrm{O}$ str, coumarin), 1098 (-C-O-C str, morpholine), 1468 ( $-\mathrm{C}=\mathrm{C}$ str, aromatic); ${ }^{1} \mathrm{H}$ NMR (DMSO, $)$ : 3.1-3.5 $\left(-\mathrm{N}\left(\mathrm{CH}_{2}\right)_{2}\right), 3.7-3.9$ $\left(-\mathrm{O}\left(\mathrm{CH}_{2}\right)_{2}\right), 6.7-7.8(\mathrm{H}, \mathrm{Ar}), 8.2(\mathrm{H}$, imine $), 4.9(\mathrm{OH}), 3.5$ $\left(\mathrm{N}-\mathrm{CH}_{3}\right)$; Mass: $494.4(\mathrm{M}+1)$.

\section{3-((1E,3E)-3-(4-)((Z)-3,4-dimethoxybenzylidene)} amino)phenyl)-3-(methylimino)prop-1-en-1-yl)-4-morpholino-2H-chromen-2-one, $6 f$

Color: Pale Yellow; IR $\left(\mathrm{KBr}, \mathrm{cm}^{-1}\right): 1652(-\mathrm{C}=\mathrm{O}$ str, chalcone), 1712 ( $-\mathrm{C}=\mathrm{O}$ str, coumarin), 1098 (-C-O-C str, morpoline), 1468 ( $-\mathrm{C}=\mathrm{C}$ str, aromatic); ${ }^{1} \mathrm{H}$ NMR (DMSO, $\delta): 3.1-3.5\left(-\mathrm{N}\left(\mathrm{CH}_{2}\right)_{2}\right), 3.7-3.9\left(-\mathrm{O}\left(\mathrm{CH}_{2}\right)_{2}\right)$,
6.7-7.8 (H, Ar), $8.3\left(\mathrm{H}\right.$, imine), $3.8\left(\mathrm{CH}_{3}\right.$, methoxy), 3.4

$\left(\mathrm{N}-\mathrm{CH}_{3}\right)$; Mass: $538.8(\mathrm{M}+1)$.

\section{3-((1E,3E)-3-(4-(((Z)-2-chlorobenzylidene)amino)}

phenyl)-3-(methylimino)prop-1-en-1-yl)-4-mor-

pholino-2H-chromen-2-one, $6 \mathrm{~g}$

Color: Dark Yellow; IR $\left(\mathrm{KBr}, \mathrm{cm}^{-1}\right): 1650(-\mathrm{C}=\mathrm{O}$ str, chalcone), 1715 ( $-\mathrm{C}=\mathrm{O}$ str, coumarin), 1097 ( $-\mathrm{C}-\mathrm{O}-\mathrm{C}$ str, morpoline), 1463 ( $-\mathrm{C}=\mathrm{C}$ str, aromatic), 765 (C$\mathrm{Cl}) ;{ }^{1} \mathrm{H}$ NMR (DMSO, $)$ : $3.1-3.5\left(-\mathrm{N}\left(\mathrm{CH}_{2}\right)_{2}\right), 3.7-3.9$ $\left(-\mathrm{O}\left(\mathrm{CH}_{2}\right)_{2}\right), 6.7-7.8(\mathrm{H}, \mathrm{Ar}), 8.2(\mathrm{H}$, imine $), 3.4\left(\mathrm{~N}-\mathrm{CH}_{3}\right)$; Mass: $513.1(\mathrm{M}+1)$.

3-((1E,3Z)-3-(4-(((Z)-3-chlorobenzylidene)amino) phenyl)-3-(methylimino)prop-1-en-1-yl)-4-morpholino-2H-chromen-2-one, $6 \mathrm{~h}$

Color: Dark Yellow; IR $\left(\mathrm{KBr}, \mathrm{cm}^{-1}\right): 1650(-\mathrm{C}=\mathrm{O}$ str, chalcone), 1715 ( $-\mathrm{C}=\mathrm{O}$ str, coumarin), 1097 ( $-\mathrm{C}-\mathrm{O}-\mathrm{C}$ str, morpoline), 1463 ( $-\mathrm{C}=\mathrm{C}$ str, aromatic), 755 (C$\mathrm{Cl}$ ); ${ }^{1} \mathrm{H}$ NMR (DMSO, $\left.\delta\right): 3.1-3.5\left(-\mathrm{N}\left(\mathrm{CH}_{2}\right)_{2}\right), 3.7-3.9$ $\left(-\mathrm{O}\left(\mathrm{CH}_{2}\right)_{2}\right), 6.7-7.8(\mathrm{H}, \mathrm{Ar}), 8.2(\mathrm{H}$, imine $), 3.5\left(\mathrm{~N}-\mathrm{CH}_{3}\right)$; Mass: $513.4(\mathrm{M}+1)$.

\section{3-((1E,3Z)-3-(4-(((Z)-benzylidene)amino)}

phenyl)-3-(methylimino)prop-1-en-1-yl)-4-mor-

pholino-2H-chromen-2-one, $6 \mathrm{i}$

Color: Dark Yellow; IR $\left(\mathrm{KBr}, \mathrm{cm}^{-1}\right): 1652(-\mathrm{C}=\mathrm{O}$ str, chalcone), 1712 ( $-\mathrm{C}=\mathrm{O}$ str, coumarin), 1098 ( $-\mathrm{C}-\mathrm{O}-\mathrm{C}$ str, morpoline), 1468 ( $-\mathrm{C}=\mathrm{C}$ str, aromatic); ${ }^{1} \mathrm{H}$ NMR (DMSO, 8$): 3.1-3.5 \quad\left(-\mathrm{N}\left(\mathrm{CH}_{2}\right)_{2}\right), \quad 3.7-3.9 \quad\left(-\mathrm{O}\left(\mathrm{CH}_{2}\right)_{2}\right)$, 6.7-7.8 (H, Ar), $8.2(\mathrm{H}$, imine $)$, 3.4 $\left(\mathrm{N}-\mathrm{CH}_{3}\right)$; Mass: 479.1 $(\mathrm{M}+1)$.

\section{3-((1E,3Z)-3-(4-(((Z)-4-methoxybenzylidene)amino)} phenyl)-3-(methylimino)prop-1-en-1-yl)-4-morpholino-2H-chromen-2-one, $6 j$

Color: Yellow; IR $\left(\mathrm{KBr}, \mathrm{cm}^{-1}\right): 1655(-\mathrm{C}=\mathrm{O}$ str, chalcone), $1718 \quad(-\mathrm{C}=\mathrm{O}$ str, coumarin), $1095 \quad(-\mathrm{C}-\mathrm{O}-\mathrm{C}$ str, morpoline), $1466(-\mathrm{C}=\mathrm{C}$ str, aromatic $) ;{ }^{1} \mathrm{H}$ NMR (DMSO, $\delta): 3.1-3.5\left(-\mathrm{N}\left(\mathrm{CH}_{2}\right)_{2}\right), 3.7-3.9\left(-\mathrm{O}\left(\mathrm{CH}_{2}\right)_{2}\right)$, 6.7$7.8(\mathrm{H}, \mathrm{Ar}), 8.2\left(\mathrm{H}\right.$, imine), $3.8\left(\mathrm{H}\right.$, methoxy), 3.4 $\left(\mathrm{N}-\mathrm{CH}_{3}\right)$; Mass: $508.3(\mathrm{M}+1)$.

\section{3-((E)-3-(4-(((Z)-4-hydroxy-3-methoxybenzylidene)} amino)phenyl)-3-oxoprop-1-en-1-yl)-4-mor-

pholino-2H-chromen-2-one, $6 \mathrm{k}$

Color: Dark Yellow; IR $\left(\mathrm{KBr}, \mathrm{cm}^{-1}\right)$ : 3600 (-OH str), 1650 ( $-\mathrm{C}=\mathrm{O}$ str, chalcone), $1717 \quad(-\mathrm{C}=\mathrm{O}$ str, coumarin), 1097 ( $-\mathrm{C}-\mathrm{O}-\mathrm{C}$ str, morpoline), $1468(-\mathrm{C}=\mathrm{C}$ str, aromatic); ${ }^{1} \mathrm{H}$ NMR (DMSO, $\left.\delta\right): 3.1-3.5\left(-\mathrm{N}\left(\mathrm{CH}_{2}\right)_{2}\right), 3.7-3.9$ $\left(-\mathrm{O}\left(\mathrm{CH}_{2}\right)_{2}\right), 6.7-7.8(\mathrm{H}, \mathrm{Ar}), 8.2(\mathrm{H}$, imine $), 5.1(\mathrm{OH}), 3.7$ $\left(\mathrm{H}\right.$, methoxy), 3.4 $\left(\mathrm{N}-\mathrm{CH}_{3}\right)$; Mass: $511.4(\mathrm{M}+1)$. 
3-((1E,3Z)-3-(4-(((Z)-3-bromobenzylidene)amino)

phenyl)-3-(methylimino)prop-1-en-1-yl)-4-mor-

pholino-2H-chromen-2-one, 61

Color: Dark Yellow; IR (KBr, cm $\left.{ }^{-1}\right): 1650$ (-C=O str, chalcone), 1710 ( $-\mathrm{C}=\mathrm{O}$ str, coumarin), 1094 ( $-\mathrm{C}-\mathrm{O}-\mathrm{C}$ str, morpoline), 1459 (-C=C str, aromatic), $610(\mathrm{C}-\mathrm{Br}) ;{ }^{1} \mathrm{H}$ NMR (DMSO, $\delta): ~ 3.1-3.5 ~\left(-N\left(\mathrm{CH}_{2}\right)_{2}\right), 3.7-3.9\left(-\mathrm{O}\left(\mathrm{CH}_{2}\right)_{2}\right), 6.7-7.8$ $(\mathrm{H}, \mathrm{Ar}), 8.2\left(\mathrm{H}\right.$, imine), $3.4\left(\mathrm{~N}-\mathrm{CH}_{3}\right)$; Mass: $557.3(\mathrm{M}+1)$.

3-((1E,3Z)-3-(4-(((Z)-4-bromobenzylidene)amino) phenyl)-3-(methylimino)prop-1-en-1-yl)-4-morpholino-2H-chromen-2-one, $6 \mathrm{~m}$

Color: Dark Yellow; IR (KBr, cm $\left.{ }^{-1}\right): 1650(-\mathrm{C}=\mathrm{O}$ str, chalcone), 1710 ( $-\mathrm{C}=\mathrm{O}$ str, coumarin), 1094 ( $-\mathrm{C}-\mathrm{O}-\mathrm{C}$ str, morpoline), 1459 ( $-\mathrm{C}=\mathrm{C}$ str, aromatic), $610(\mathrm{C}-\mathrm{Br}) ;{ }^{1} \mathrm{H}$ NMR (DMSO, $)$ : 3.1-3.5 $\left(-\mathrm{N}\left(\mathrm{CH}_{2}\right)_{2}\right), 3.7-3.9\left(-\mathrm{O}\left(\mathrm{CH}_{2}\right)_{2}\right), 6.7-7.8$ $(\mathrm{H}, \mathrm{Ar}), 8.2(\mathrm{H}$, imine $), 3.5\left(\mathrm{~N}-\mathrm{CH}_{3}\right)$; Mass: $557.6(\mathrm{M}+1)$.

3-((1E,3Z)-3-(4-(((Z)-4-chlorobenzylidene)amino) phenyl)-3-(methylimino)prop-1-en-1-yl)-4-morpholino-2H-chromen-2-one, 6 n Color: Dark Yellow; IR (KBr, cm $\left.{ }^{-1}\right): 1652$ (-C=O str, chalcone), 1710 (-C=O str, coumarin), 1097 (-C-O-C str, morpoline), 1463 (-C=C str, aromatic), $763(\mathrm{C}-\mathrm{Cl}) ;{ }^{1} \mathrm{H}$ NMR (DMSO, $)$ : $3.1-3.5\left(-\mathrm{N}\left(\mathrm{CH}_{2}\right)_{2}\right), 3.7-3.9\left(-\mathrm{O}\left(\mathrm{CH}_{2}\right)_{2}\right), 6.7-7.8$ $(\mathrm{H}, \mathrm{Ar}), 8.2\left(\mathrm{H}\right.$, imine), $3.5\left(\mathrm{~N}-\mathrm{CH}_{3}\right)$; Mass: $523.2(\mathrm{M}+1)$.

\section{3-((1E,3Z)-3-(4-(((Z)-4-(dimethylamino)benzylidene)} amino)phenyl)-3-(methylimino)prop-1-en-1-yl)-4-morpholino-2H-chromen-2-one, 60

Color: Pale Yellow; IR $\left(\mathrm{KBr}, \mathrm{cm}^{-1}\right): 1652(-\mathrm{C}=\mathrm{O}$ str, chalcone), 1712 ( $-\mathrm{C}=\mathrm{O}$ str, coumarin), 1096 (-C-O-C str, morpoline), 1468 ( $-\mathrm{C}=\mathrm{C}$ str, aromatic); $1 \mathrm{H} \mathrm{NMR}$ (DMSO, $\delta): 3.1-3.5\left(-\mathrm{N}\left(\mathrm{CH}_{2}\right)_{2}\right), 3.7-3.9\left(-\mathrm{O}\left(\mathrm{CH}_{2}\right)_{2}\right)$, 6.7-7.8 (H, Ar), $8.2\left(\mathrm{H}\right.$, imine), $2.9\left(\mathrm{H}, \mathrm{N}-\mathrm{CH}_{3}\right), 3.5$ $\left(\mathrm{N}-\mathrm{CH}_{3}\right)$; Mass: $521.6(\mathrm{M}+1)$.

\section{In-vitro antioxidant activity}

The in vitro antioxidant activity of the synthesized compounds $\mathbf{5 a - 0}$ and $\mathbf{6 a - 0}$ was determined by two different methods using ascorbic acid as the standard.

\section{DPPH method}

The free radical scavenging activity of the synthesized molecules was measured in terms of hydrogen donating or radical scavenging ability using the stable radical DPPH [23]. The test samples $(10-100 \mu \mathrm{L})$ were prepared in DMSO and were mixed with $1.0 \mathrm{~mL}$ of DPPH solution and filled up with methanol to a final volume of $4 \mathrm{~mL}$.
Absorbance of the resulting solution was measured at $517 \mathrm{~nm}$ in a visible spectrophotometer. Ascorbic acid was used as the reference compound. Lower absorbance of the reaction mixture indicated higher free radical scavenging activity. Radical scavenging activity was expressed as the inhibition percentage of free radical by the sample and was calculated using the following formula:

$$
\text { \%inhibition }=\frac{(A o-A t)}{A o} \times 100
$$

where $A$ o is the absorbance of the control (blank, without sample) and $A t$ is the absorbance in the presence of the test samples. All tests were performed in triplicate and the results were expressed as mean values \pm standard deviations.

\section{Hydroxyl radical scavenging method}

The test samples $(10-100 \mu \mathrm{L})$ were prepared in DMSO and $1 \mathrm{~mL}$ of iron EDTA solution, $0.5 \mathrm{~mL}$ of EDTA solution, $1 \mathrm{~mL}$ of DMSO and $0.5 \mathrm{~mL}$ of ascorbic acid were added to it. The mixture was incubated in a boiling water bath at 80 to $90{ }^{\circ} \mathrm{C}$ for $15 \mathrm{~min}$. After incubation, $1 \mathrm{~mL}$ of ice cold TCA and $3 \mathrm{~mL}$ of Nash reagent were added and the reaction mixture was incubated at room temperature for $15 \mathrm{~min}$. The absorbance was read at $412 \mathrm{~nm}$. The \% hydroxyl radical scavenging activity is calculated by the following formula

$$
\% H R S A=\frac{\text { Abs control }- \text { Abs sample }}{\text { Abs control }} \times 100
$$

where, HRSA is the Hydroxyl Radical Scavenging Activity, Abs control is the absorbance of control and Abs sample is the absorbance of the test solution.

\section{Results}

Chemistry

Table 1 presents the physical data and chemical structures of all the synthesized compounds.

\section{Antioxidant action}

The antioxidant activity displayed by the synthesized compounds against DPPH and hydroxyl radicals is presented in Tables 2 and 3.

\section{Discussion}

Chemistry

Two series of newer coumarin-chalcone conjugates $5 \mathrm{a}-\mathrm{o}$ and 6a-o were synthesized utilizing Scheme 1. Carbaldehyde 2 resulted by the reaction of 4-hydroxy coumarin 
Prasad and Loksh Futur J Pharm Sci

(2021) 7:193

Page 7 of 12

Table 1 Physical characterization data and chemical structure of $5 \mathbf{a}-\mathbf{o} \& 6 \mathbf{a}-\mathbf{0}$

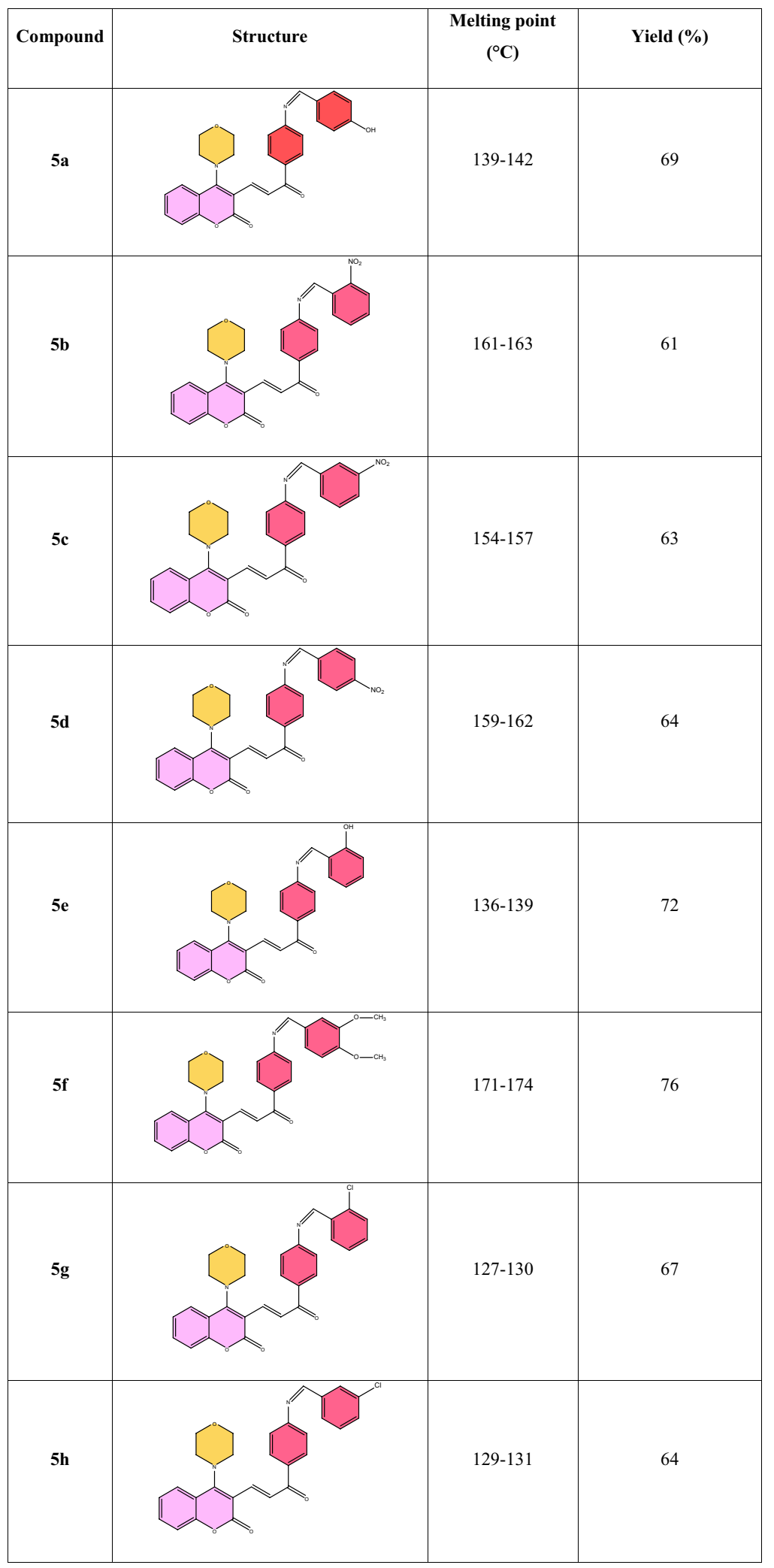


Table 1 (continued)

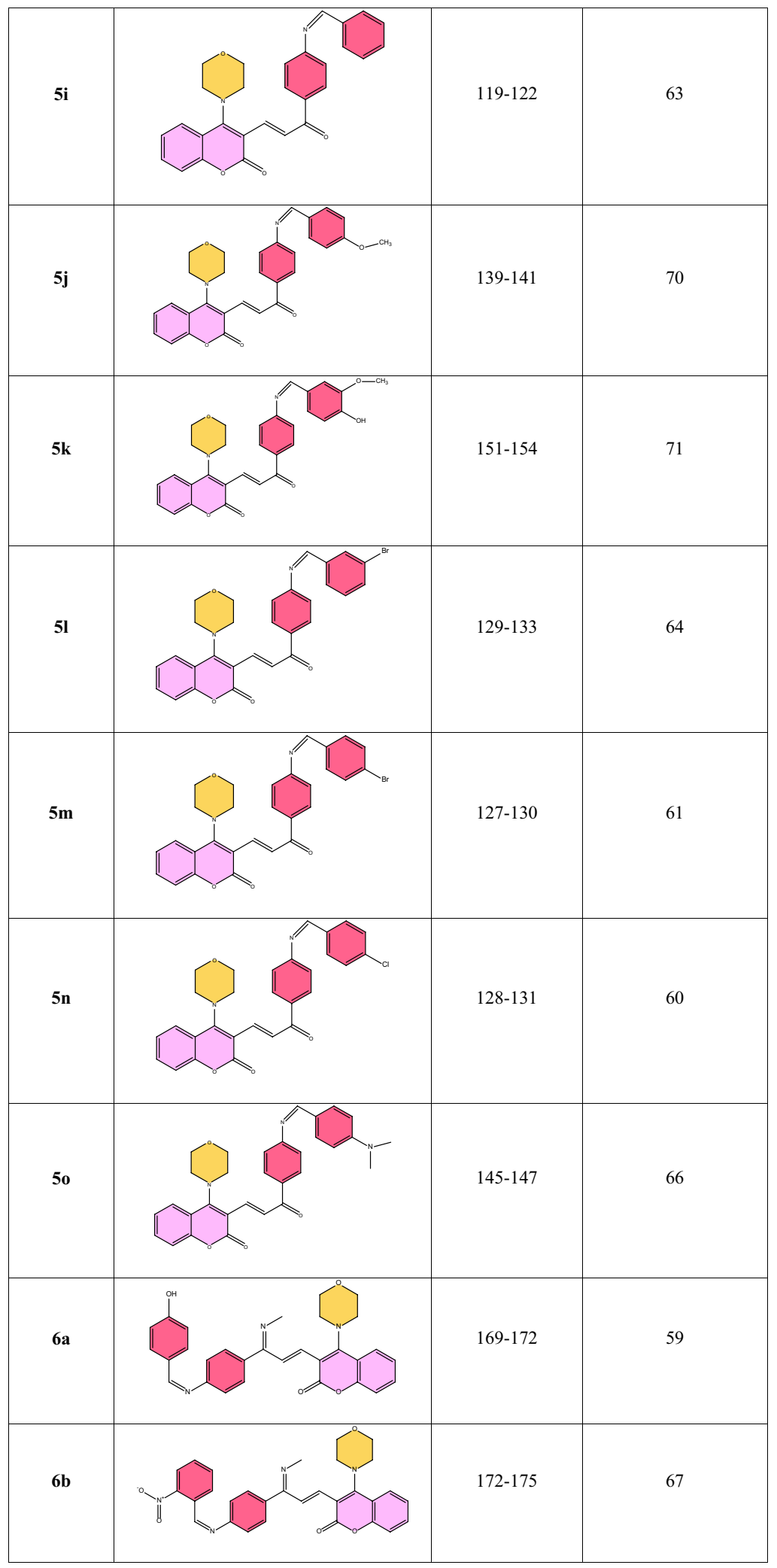


Table 1 (continued)

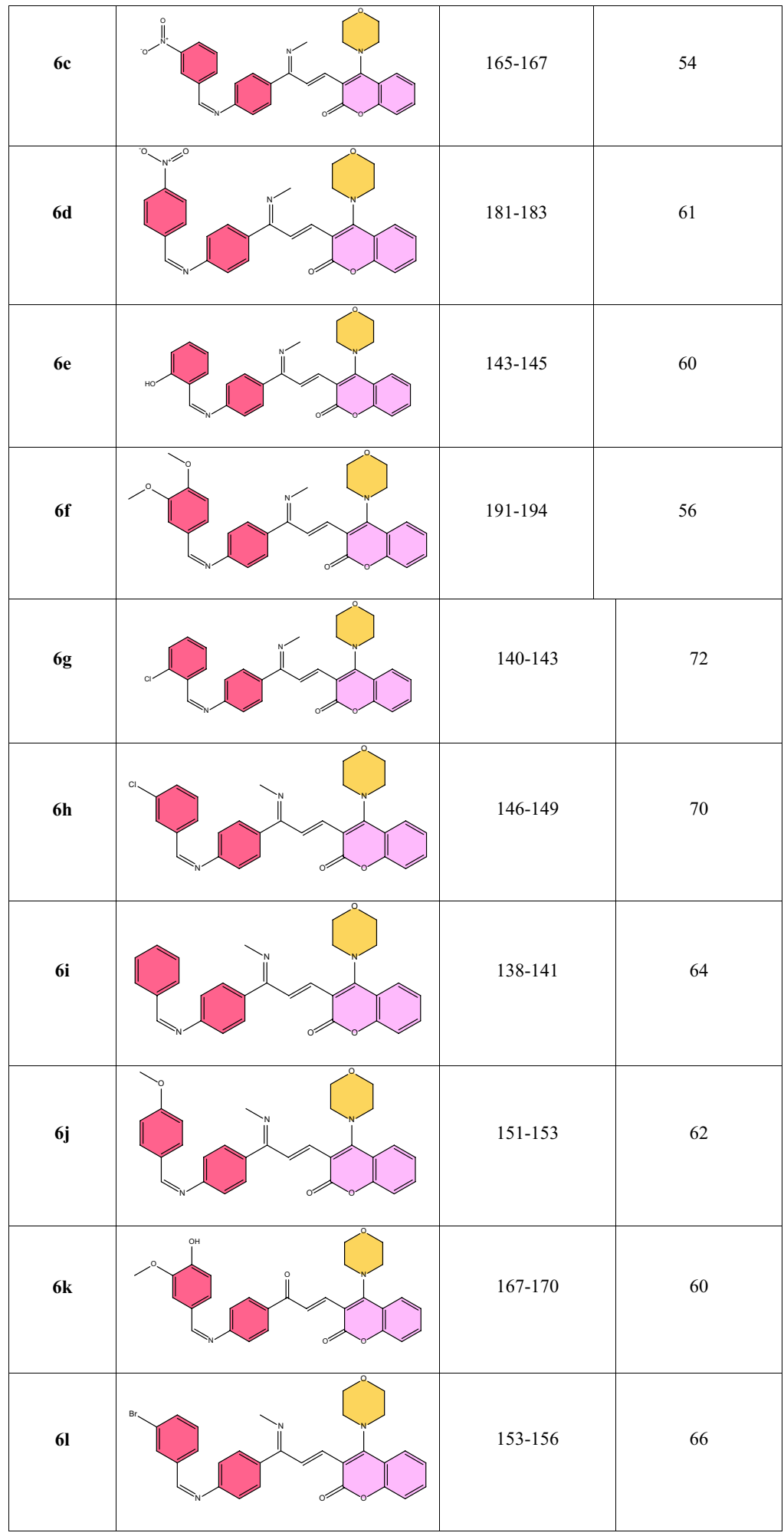


Table 1 (continued)

\begin{tabular}{|c|c|c|}
\hline $6 \mathrm{~m}$ & $147-149$ & 61 \\
\hline $6 n$ & $143-146$ & 63 \\
\hline 60 & $161-163$ & 65 \\
\hline
\end{tabular}

Table $2 I_{50}$ values of $5 \mathbf{a}-\mathbf{0}$

\begin{tabular}{lll}
\hline Compound & \multicolumn{1}{l}{$\mathbf{I C}_{\mathbf{5 0}}$} \\
\cline { 2 - 3 } & $\mathbf{D P P H}$ & HRSA \\
\hline $\mathbf{5 a}$ & $17.1 \pm 0.19$ & $16.9 \pm 0.01$ \\
$\mathbf{5 b}$ & $37.4 \pm 0.08$ & $33.8 \pm 0.10$ \\
$\mathbf{5 b}$ & $35.7 \pm 0.21$ & $33.1 \pm 0.35$ \\
$\mathbf{5 d}$ & $35.2 \pm 0.11$ & $33.0 \pm 0.56$ \\
$\mathbf{5 e}$ & $17.9 \pm 0.03$ & $16.4 \pm 0.17$ \\
$\mathbf{5 f}$ & $19.6 \pm 0.07$ & $18.1 \pm 0.73$ \\
$\mathbf{5 g}$ & $27.2 \pm 0.61$ & $26.7 \pm 0.21$ \\
$\mathbf{5 h}$ & $27.1 \pm 0.26$ & $25.9 \pm 0.11$ \\
$\mathbf{5 i}$ & $26.7 \pm 0.29$ & $24.9 \pm 0.14$ \\
$\mathbf{5 j}$ & $21.3 \pm 0.47$ & $19.8 \pm 0.25$ \\
$\mathbf{5 k}$ & $16.6 \pm 0.10$ & $15.5 \pm 0.66$ \\
$\mathbf{5 I}$ & $29.1 \pm 0.53$ & $28.6 \pm 0.05$ \\
$\mathbf{5 m}$ & $29.5 \pm 0.67$ & $27.7 \pm 0.26$ \\
$\mathbf{5 n}$ & $27.1 \pm 0.30$ & $26.0 \pm 0.13$ \\
$\mathbf{5 0}$ & $15.3 \pm 0.26$ & $14.4 \pm 0.29$ \\
$\mathbf{A s c o r b i c ~ a c i d}$ & $13.8 \pm 0.11$ & $15.7 \pm 0.65$ \\
\hline
\end{tabular}

1 with Vilsmeier-Haack reagent leading to formylation of the electron rich ring [24]. Compound 2 undergoes nucleophilic aromatic substitution with morpholine to yield the compound $\mathbf{3}$ which on condensation with amino acetophenone under the conditions of ClaisenSchmidt reaction yielded the chalcone conjugates 4 . The coumarin-chalcone conjugates were further condensed at reflux conditions with aromatic aldehydes and methyl amine to obtain compounds $5 \mathbf{a}-\mathbf{o}$ and $\mathbf{6 a}-\mathbf{o}$. The optimization of the reaction for completion and purity was performed throughout using TLC. The structures of the
Table $3 I C_{50}$ values of $6 a-0$

\begin{tabular}{lll}
\hline Compound & \multicolumn{1}{l}{$\mathbf{I} \mathbf{5 0}$} \\
\cline { 2 - 3 } & DPPH & HRSA \\
\hline $\mathbf{6 a}$ & $23.9 \pm 0.15$ & $19.1 \pm 0.36$ \\
$\mathbf{6 b}$ & $46.5 \pm 0.04$ & $44.8 \pm 0.34$ \\
$\mathbf{6 c}$ & $44.9 \pm 0.17$ & $42.1 \pm 0.76$ \\
$\mathbf{6 d}$ & $46.1 \pm 0.56$ & $43.7 \pm 0.18$ \\
$\mathbf{6 e}$ & $24.3 \pm 0.11$ & $19.3 \pm 0.21$ \\
$\mathbf{6 f}$ & $18.1 \pm 0.54$ & $16.0 \pm 0.08$ \\
$\mathbf{6 g}$ & $34.1 \pm 0.01$ & $32.9 \pm 0.40$ \\
$\mathbf{6 h}$ & $32.7 \pm 0.35$ & $32.0 \pm 0.08$ \\
$\mathbf{6 i}$ & $28.2 \pm 0.13$ & $26.5 \pm 0.16$ \\
$\mathbf{6 j}$ & $19.9 \pm 0.26$ & $16.3 \pm 0.02$ \\
$\mathbf{6 k}$ & $17.5 \pm 0.08$ & $15.2 \pm 0.97$ \\
$\mathbf{6 I}$ & $39.6 \pm 0.05$ & $37.2 \pm 0.29$ \\
$\mathbf{6 m}$ & $39.2 \pm 0.26$ & $36.5 \pm 0.76$ \\
$\mathbf{6 n}$ & $32.9 \pm 0.32$ & $32.5 \pm 0.01$ \\
$\mathbf{6 0}$ & $16.0 \pm 0.03$ & $14.9 \pm 0.12$ \\
Ascorbic acid & $13.8 \pm 0.11$ & $15.7 \pm 0.65$ \\
\hline
\end{tabular}

synthesized molecules were characterized by ${ }^{1} \mathrm{H}$ NMR, IR and mass spectral studies.

The ${ }^{1} \mathrm{H}$ NMR spectra of compound $\mathbf{5 a}-\mathbf{o}$ exhibited peaks in the region of 3.1-3.9 corresponding to $-\mathrm{N}\left(\mathrm{CH}_{2}\right)_{2}$ and $-\mathrm{O}\left(\mathrm{CH}_{2}\right)_{2} ; 6.7-7.8$ due to aromatic protons, the peaks due to $\alpha, \beta$-unsaturation of chalcones; 8.2 owing to the imine protons. Additionally, the signals due to the hydroxyl and methoxy protons were also found in the corresponding compounds. In the ${ }^{1} \mathrm{H}$ NMR spectra of compound 6a-o additional peak at 3.3-3.5 was obtained due the methyl protons of methylamine. The mass 
spectra of all the compounds displayed $\mathrm{M}+1$ peaks corresponding to their molecular formula.

\section{Antioxidant action}

As known, free radical scavenging is one of most perceived mechanisms for any antioxidant to inhibit oxidation of lipids. The standard assay protocols to evaluate the free radical scavenging activity include the DPPH and the hydroxyl radical scavenging activity assays. The antioxidant potential of the compounds $5 \mathbf{a}-\mathbf{o}$ and $\mathbf{6 a - o}$ was assessed using these two methods using ascorbic acid as the standard.

DPPH radicals are stable free radicals whose radical character is neutralized in the presence of molecules that may donate $\mathrm{H}$ atoms. The reduction of the DPPH radical can be spectrophotometrically determined by the decreased absorbance at $517 \mathrm{~nm}$ caused due to antioxidants.

Hydroxyl radical scavenging assay is used to find the antioxidant activity of test compounds against free hydroxyl radicals like hydrogen peroxide (known cause damage to the cells). The model used is ascorbic acidiron-EDTA model of hydroxyl radical generating system. This is a totally aqueous system wherein ascorbic acid, iron and EDTA combine with each other to generate hydroxyl radicals.

As it can be seen from results tabulated in Table 3, compounds 5a, 5e, 5f, 5k and 5o had DPPH and hydroxyl radical scavenging activity comparable to the standard drug ascorbic acid while the remaining compounds exhibited very high $\mathrm{IC}_{50}$ values. It was also observed that the $\mathrm{IC}_{50}$ values of the compounds were lower for hydroxyl radical scavenging (14.4 to $33.8 \mu \mathrm{g} / \mathrm{mL}$ ) as compared to DPPH radical scavenging (15.3 to $37.4 \mu \mathrm{g} / \mathrm{mL}$ ). Compounds 50 and $\mathbf{5} \mathbf{k}$ were found to be exhibiting better inhibition of the hydroxyl radical with $\mathrm{IC}_{50}$ values 14.4 and 15.5 respectively as compared to ascorbic acid (15.7).

The results highlighted the importance of the carbonyl group of the chalcone molecule in the antioxidant action as the $\mathrm{IC}_{50}$ values of compounds $\mathbf{6 a - 0}$ was comparatively poor to that of $5 \mathbf{a}-\mathbf{o}$. The absence of the carbonyl carbon could be attributed to the decreased antioxidant action of 6a-o. A similar decrease in antioxidant potential was reported by Lahsasni et al. [25] where they condensed the carbonyl carbon and the double bond into pyridine ring to obtain compounds which were less potential antioxidants when compared to the corresponding $\alpha, \beta$ - unsaturated carbonyl compounds. The excellent antioxidant capacity of $5 \mathbf{a}, 5 \mathbf{e}, \mathbf{5 f}, 5 \mathbf{k}$ and 50 reaffirmed the concept that organic molecules containing electron donating groups have better capacity to neutralize free radicals and oppose oxidation [26].

\section{Conclusions}

Two series of coumarin-chalcone hybrid molecules were synthesized in good yields using Vilsmeier-Haack, nucleophilic aromatic substitution and Claisen-Schmidt condensation reaction and characterized by spectral studies. The synthesized compounds exhibited good antioxidant potential against DPPH and hydroxyl radicals in the scavenging assays with compounds $\mathbf{5 0}$ and $\mathbf{5 k}$ being the most significant against the tested radicals.

\section{Abbreviations \\ FTIR: Fourier-Transform Infrared Spectroscopy; DMF: Dimethylformamide; TLC: Thin layer chromatography; NMR: Nuclear Magnetic Resonance; HRSA: Hydroxyl Radical Scavenging Activity; DPPH: 2,2-Diphenyl-1-picrylhydrazyl; DMSO: Dimethyl sulfoxide; EDTA: Ethylene Diamine Tetra Acetic Acid.}

\section{Supplementary Information}

The online version contains supplementary material available at https://doi. org/10.1186/s43094-021-00340-1.

Additional file 1. Scheme 1.

Acknowledgements

Not applicable.

Authors' contributions

RKP performed all the synthetic and biological activity work. KRL was involved in interpreting the results and preparing the manuscript. All authors read and approved the manuscript.

Funding

Not applicable.

Availability of data and materials

Not applicable.

\section{Declarations}

Ethics approval and consent to participate

Not applicable.

Consent for publication

Not applicable.

Competing interests

The authors declare that they have no competing interests.

Received: 3 February 2021 Accepted: 17 September 2021

Published online: 26 September 2021

References

1. Aoyama Y, Katayama T, Yamamoto M, Tanaka H, Kon K (1992) A new antitumor antibiotic product, demethylchartreusin. Isol Biol Activities J Antibiot 45(6):875-878

2. Al-Amiery AA, Al-Majedy YK, Al-Duhaidahawi D, Kadhum AAH, Mohamad AB (2016) Green antioxidants: synthesis and scavenging activity of coumarin-thiadiazoles as potential antioxidants complemented by molecular modeling studies. Free Radic Antioxidants 6(2):173-177

3. Al-Amiery AA, Kadhum AAH, Mohamad AA (2012) Antifungal activities of new coumarins. Molecules 17(5):5713-5723 
4. Al-Azawi F, Al-Baghdadi S, Mohamed A, Al-Amiery A, Abed T, Mohammed S, Kadhum AAH, Mohamad AB (2016) Synthesis, inhibition effects and quantum chemical studies of a novel coumarin derivative on the corrosion of mild steel in. Chem Cent J 10(1):1-9

5. Al-Ayed AS (2011) Synthesis, spectroscopy and electrochemistry of new 3-(5-Ar-yl-4,5-Dihydro-1H-Pyrazol-3-yl)-4-hydroxy-2H-chromene-2-one 4, 5 as a novel class of potential anti- bacterial and antioxidant derivatives. Int J Org Chem 1(03):87-96

6. Al-Amiery AA, Kadhum AAH, Mohamad AB, Musa AY, Li CJ (2013) Electrochemical study on newly synthesized chlorocurcumin as an inhibitor for mild steel corrosion in hydrochloric acid. Materials 6(12):5466-5477

7. Al-Majedy Y, Al-Amiery A, Khadum AA, Mohamad AB (2017) Antioxidant activity of coumarins. Syst Rev Pharm 8(1):24-30

8. Stepanic V, Matijasic M, Horvat T, Verbanac D, Kucerová-Chlupácová M, Saso L, Žarkovic N (2019) Antioxidant activities of alkyl substituted pyrazine derivatives of chalcones - in vitro and in silico study. Antioxidants 8:90-101

9. Mishra R, Jain S (2013) In vitro anti-malarial evaluation of some thiazole containing chalcone derivatives. PharmacologyOnLine 2:106-109

10. Mishra R, Jain S (2013) Investigation of antimicrobial potential of some thiazolyl chalcone derivatives. PharmacologyOnline 1:190-193

11. Milan C, Maja M, Tomislav B, Nela D, Valentina R (2009) Design and synthesis of some thiazolidin-4-ones based on(7-hydroxy-2-oxo-2hchromen-4-yl) acetic acid. Molecules 14(7):2501-2513

12. Jayashree BS, Kumar A, Pai A (2011) Synthesis characterization and antidiabetic evaluation novel coumarin analogues. Pharmacol Online 3:1061-1076

13. Garazd MM, Muzychka OV, Voyk Al, Nagorichna IV. Ogorodniichuk AS (2007) Modified coumarins. 27. Synthesis and antioxidant activity of 3-substituted 5,7-dihydroxy-4-methyl coumarins. Chem Nat Compd 43(1):19-23.

14. Hamdi N, Puerta MC, Valerga P (2008) Synthesis, structure, antimicrobial and antioxidant investigations of dicoumarol and related compounds. Eur J Med Chem 43(11):2541-2548

15. Tripathi N, Patel P, Mishra R, Mishra B, Balasubramaniam A (2013) Chemical and pharmacological evaluation of Pyrimidine derivatives of Thiazolidinedion. Asian J Pharm Educ Res 2(2):43-57
16. Mishra BJ (2017) Synthesis of 1,8-Napthyridine derivatives and their evaluation as possible antiepileptic agents. J Pharmacol Biomed 1(1):1-8

17. d'Oliveira GDC, Moura AF, de Moraes MO, Perez CN, Lião LM (2018) Synthesis, characterization and evaluation of in vitro antitumor activities of novel chalcone-quinolinone hybrid compounds. J Braz Chem Soc 29(11):2308-2325

18. Tandel H, Chikalia KH, Patel SK (2019) Synthesis and antibacterial activity of novel coumarin-chalcone hybrids. Indian J Chem 58B:594-602

19. Srikrishna D, Dubey PK (2017) Facile, stepwise and diversity oriented synthesis of 3-(2-Oxo-2H-Chromen-3-yl)-1-Phenyl-1H-Pyrazole-4-carbaldehydes. J Chem Pharm Res 9(11):99-108

20. Iliev BI, Ivanov IC (2001) 4-Morpholino-2-oxo-2H-chromene-3-carbaldehyde. Molecules 6:M218

21. Al-Ayed AA (2011) Synthesis of new substituted chromen[4,3-c]pyrazol4-ones and their antioxidant activities. Molecules 16:10292-10302

22. Avalakki AS, Jadhav SB, Bandawane DD, Bhalekar PA (2019) Synthesis and antidiabetic evaluation of some novel compounds. Indian J Chem 58B:849-854

23. Blois MS (1958) Antioxidant determinations by the use of a stable free radical. Nature 181(4617):1199-1200

24. Dongamati A, Bachi Reddy V, Mdderla S, Vijaya Lakshmi B (2017) Microwave assisted synthesis of substituted 4-chloro-8-methyl-2(1,3-diphenyl-1H-pyrazol-4-yl)-1,5-dioxa-2H-phenanthren-6-ones and their antimicrobial activity. J Serbian Chem Soc 82(2):117-125

25. Lahsasni SA, Al Korbi FH, Aljaber NAZ (2014) Synthesis, characterization and evaluation of antioxidant activities of some novel chalcones analogues. Chem Central J 8: 32; doi: https://doi.org/10.1186/ 1752-153X-8-32.

26. Mohana KN, Pradeep Kumar CB (2013) Synthesis and antioxidant activity of 2-amino-5-methylthiazol derivatives containing 1,3,4-oxadiazole2-thiol moiety. ISRN Org Chem. https://doi.org/10.1155/2013/620718

\section{Publisher's Note}

Springer Nature remains neutral with regard to jurisdictional claims in published maps and institutional affiliations.

\section{Submit your manuscript to a SpringerOpen ${ }^{\circ}$ journal and benefit from:}

- Convenient online submission

- Rigorous peer review

- Open access: articles freely available online

- High visibility within the field

- Retaining the copyright to your article

Submit your next manuscript at $\boldsymbol{\nabla}$ springeropen.com 